\title{
NEWS FROM THE RUSSIAN FAR EAST
}

\author{
By Eugenyi A. Makarchenko \\ Institute of Biology and Soil Sciences, Far East Branch, Russian Academy of Sciences, \\ (FEB RAS) 690022, Vladivostok, Russia
}

Last year I introduced my working group, which consists of Marina A. Makarchenko (Orthocladiinae), Oksana V. Zorina (Chironominae) and Eugenyi A. Makarchenko (Podonominae, Diamesinae, Prodiamesinae and Orthocladiinae). The main purpose of our investigation is to prepare a Key for Chironomidae (males, pupae and larvae) of the Russian Far East.

During the second part of 1999 and in 2000 we have studied the taxonomy of the Orthocladiinae from Vrangel Island, Chukchi Peninsula and Primorye (territory from Vladivostok to Khabarovsk), and Chironominae (tribe Chironomini) from the south part of the Russian Far East (Primorye Territory, Khabarovsk Region, Sakhalin and Kurile Islands) (Fig. 1).

Fig.1. The map of the Russian Far East

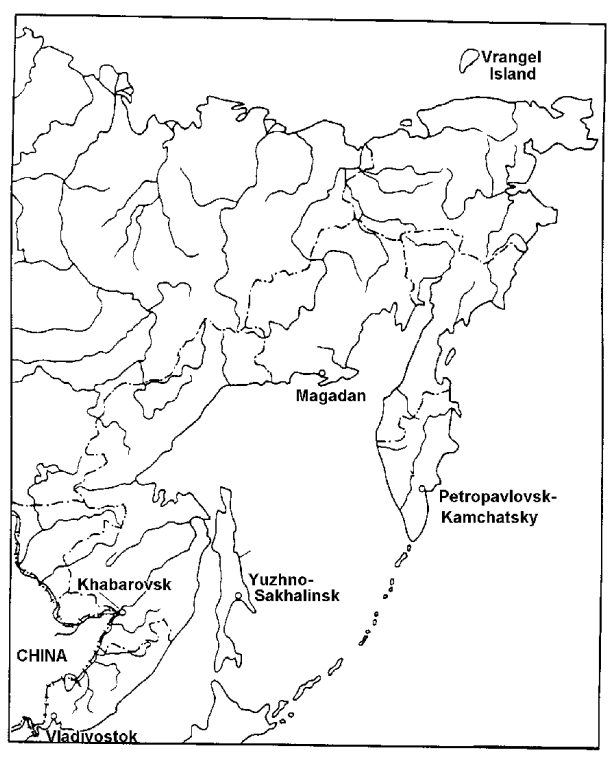

From Vrangel Island we identified for the first time 27 species of Orthocladiinae: Bryophaenocladius nitidicolis (GOETGH.), Chaetocladius festivus (HO L M G R.), Chaetocladius sp. n. 1, Chaetocladius sp.n. 2, Chaetocladius sp.n. 3, Corynoneura arctica KIEFF., Cricotopus (C.) tibialis (MG.), Hydrobaenus fusistylus (GO E T G H.), Limnophyes brachytomus (KIEFF.), L. pumilio (HolmGR.), Limnophyes sp.n. 1, Limnophyes sp.n. 2, Metriocnemus eurynotus (HoLMGR.), M. intergerivus SÆTHER, M. ursinus (HolmGR.), Orthocladius (Eudactylocladius) gelidus KIEFF., O. (s.str.) hazenensis SOPONIS, O. (Pogonocladius) consobrinus (HoLMGR.), Pseudosmittia recta (ED W.), P. nanseni (KIEFF.), Rheocricotopus (s.str.) reduncus SÆTHER et SCH N L L, Smittia extrema (HolMGR.), S. joganbrevicosta SA S A et OKAZAWA, Tokunagaia kibunensis (TOK.), $T$. rectangularis (GOETGH.).

Sixty five species of Orthocladiinae genera Antillocladius, Bryophenocladius, Camptocladius, Corynoneura, Cricotopus (s.str.), C. (Pseudocricotopus), C. (Nostococladius), C. (Isocladius), Eukiefferiella, Gymnometriocnemus, Heterotrissocladius, Hydrob a e $n$ us, Krenosmittia, Limnophyes, Metriocnemus, Mesosmittia, Nanocladius, Orthocladius (s.str.), O. (Euorthocladius), Ps eudorthocladius, Parametriocnemus, Paratrichocladius, Pseudosmittia, Smittia, Stilocladius, Thienemanniella, Tsudoyusurika, Tvetenia from Primorye Territory were found, from which seven species of Bryophaenocladius, C. (Pseudocricotopus), Limnophyes, Pseudorthocladius, Smittia, Stilocladius and Tsudayusurika, appear to be new for science. One species, Hydrobaenus calvescens SÆTHER, is recorded for the Palaearctic region for the first time.

One hundred ninety two species of Chironomini from the south part of the Russian Far East were identified, of which about 20 species of the genera Cryptochironomus, Cryptotendipes, Dicrotendipes, Microtendipes, Paratendipes, Polypedilum, Stenochironomus and Stictochironomus appear to be new to science; 9 species, Harnischia incidata TOWNES, Kloosia dorsenna (SÆTHER), Phaenopsectra? profusa (TOWNES), P. ? dyari (TOWNES), Polypedilum exilicaudatus SÆTHER et SUNDAL, $P$. albinodus TOWNES, Stictochironomus ? lutosus (TOWNES), S. ? naevus (MITCHELL), are recorded for Palaearctic region for the first time. Twenty species were known previously only from Japan.

More detailed information can be found on the Russian Chironomid Home Page, which was opened in Vladivostok in March 14, 2000. Address of this site is:

http:// www.tendipes.febras.ru 